identified in the cytoplasm of non-trophoblastic tumours of the breast and gastrointestinal tract using immunohistochemical techniques. ${ }^{2}$ Since the development of a sensitive and specific radioimmunoassay it has been possible to measure low levels $(\mu \mathrm{g} / \mathrm{l})$ of the protein. ${ }^{3}$ Previously this has not been possible using less sensitive assays based on immunoprecipitation systems. The detection limit of the radioimmunoassay is $8 \mu \mathrm{g} / \mathrm{l}$ and the material was not detected in 100 normal men and non-pregnant women volunteers.

The present report is the first describing circulating levels of SP in the male, and probably the molecule was produced by the testicular teratoma. The concentrations of $\mathrm{SP}_{1}$ in this case were low $(<150 \mu \mathrm{g} / \mathrm{l})$ in comparison with those found in late pregnancy $(250 \mathrm{mg} / \mathrm{l})$. The concentration of $\mathrm{SP}_{1}$ measured 10 days after orchidectomy was higher than can be accounted for by the half-life of this protein (30-40 hours) and, although HCG was not detected at this time, the existence of a metastatic deposit remains a possibility.

As minute amounts of $\mathrm{SP}_{1}$ in plasma can now be measured, we suggest that the detection of $\mathrm{SP}_{1}$ in the circulation may present an additional tool in the diagnosis and monitoring of patients with malignant disease.

We gratefully acknowledge the assistance of Miss D Jeffrey, Professor T Chard, and Mr D F Ellison Nash, and thank the last for the opportunity to study his patient. J G Grudzinskas is supported by the World Health Organisation.

${ }^{1}$ Bohn, H, Protides of Biological Fluids, 1976, 24, 117.

${ }^{2}$ Horne, C H W, et al, Protides of Biological Fluids, 1976, 24, 567

${ }^{3}$ Grudzinskas, J G, et al, Lancet, 1977, 1, 333.

${ }^{4}$ Bohn, H, Archiv für Gynäkologie, 1971, 210, 440.

${ }^{5}$ Lin, T H, et al, American fournal of Obstetrics and Gynecology, 1974, 118, 223.

(Accepted 1 February 1977)

Department of Haematology, St Bartholomew's Hospital, London EC1

S A N JOHNSON, MRCS, MB, registrar

Departments of Reproductive Physiology, and Obstetrics and Gynaecology, St Bartholomew's Hospital Medical College and the London Hospital Medical College, London

J G GRUDZINSKAS, MRCOG, WHO research fellow Y B GORDON, MRCOG, lecturer

A T M AL-ANI, BSC, MPHIL, research fellow

\section{Vitamin D resistance in hypoparathyroidism with medullary carcinoma of the thyroid}

Until recently hypoparathyroidism could only be treated with vitamin $\mathrm{D}$ or dihydrotachysterol in large doses. The dose of vitamin D needed (1.0-2.5 mg daily) was some 500 to 1000 times greater than the physiological requirement. ${ }^{1}$ It has recently become clear why such large doses were needed. Parathyroid hormone (PTH) probably acts by promoting the formation in the kidney of 1,25-dihydroxycholecalciferol, the active metabolite of vitamin $\mathrm{D}_{3}$; without PTH this step is defective. Hypoparathyroidism responds to as little as $2 \mu \mathrm{g}$ 1,25-dihydroxycholecalciferol daily. ${ }^{2}$ In most patients with hypoparathyroidism the condition can be controlled with less than $2.5 \mathrm{mg}$ vitamin D daily. A few patients need much higher doses of vitamin $\mathrm{D}$, and one such patient, who also had medullary carcinoma of the thyroid, provided an opportunity for observing the possible interrelations of PTH, calcitonin, and vitamin D.

\section{Case report}

The patient first presented aged 16 with a swelling in the neck: a small tumour was removed from the thyroid and reported to be a benign adenoma. The swelling recurred at the age of 22 , and enlarged slowly. He presented again at the age of 34 , when the goitre had become extremely large and tender. He had also noted increasing hoarseness. He had an enormous tender bossellated mass in the neck that extended over the manubrium. $X$-ray examination showed that the trachea was displaced by the mass, which had flecks of calcification.

The neck was explored by RP and AGM; the mass was removed and a radical dissection carried out. The excised tissue consisted mainly of undifferentiated polyhedral-cell carcinoma with many mitotic figures, but also small areas of follicular carcinoma. Within two days of the operation the patient became hypocalcaemic and was treated with oral calcium and calciferol ( $1.25 \mathrm{mg}$ daily). For the next 18 months he complained of nausea and of paraesthesiae in the feet and hands. He remained hypocalcaemic despite increasing doses of calcium and was referred to an endocrine clinic. At this stage the plasma calcium was $1.90 \mathrm{mmol} / 1(7.6 \mathrm{mg} / 100 \mathrm{ml})$ and inorganic phosphate $1.55 \mathrm{mmol} / 1(4.8 \mathrm{mg} / 100 \mathrm{ml})$. We felt that he needed an increased dose of calciferol but that the large dose of calcium might have caused his nausea. The dose of calcium was reduced and that of calciferol increased. His symptoms were relieved and his plasma calcium became normal only when the dose of calciferol was $10 \mathrm{mg}$ daily.

Two years after his operation the goitre recurred; he also complained of diarrhoea for which no cause could be found. Accordingly the plasma calcitonin was estimated and found to be greatly raised at $28.8 \mu \mathrm{g} / 1$. The histological appearances were reviewed and now thought to be consistent with medullary carcinoma. Soon afterwards he noted pleuritic chest pain and was found to have pleural metastases. $\mathrm{He}$ did not respond to cytotoxic therapy and died three years after his operation.

\section{Comment}

Extreme resistance to vitamin $\mathrm{D}$ is uncommon. Possible causes include magnesium deficiency ${ }^{3}$ and malabsorption but there was no evidence of either. The high plasma concentration of calcitonin may have been significant. Calcitonin inhibits the formation of 1,25 dihydroxycholecalciferol in isolated renal tubules ${ }^{4}$ and Avioli $^{5}$ has suggested that calcitonin promotes the formation of the physiologically inactive 24,25-dihydroxycholecalciferol, just as PTH promotes the production of 1,25 -dihydroxycholecalciferol (figure). If this is correct our patient may have been resistant to vitamin $D$ because he not only lacked PTH but also had high plasma concentrations of calcitonin

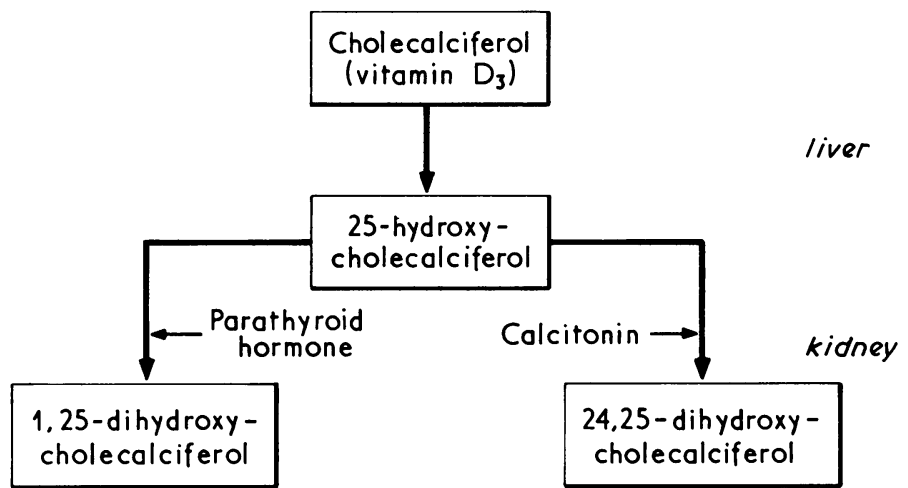

Possible role of calcitonin in metabolism of vitamin $\mathrm{D}_{3}$ (cholecalciferol). It is suggested that calcitonin promotes the production of 24,25-dihydroxycholecalciferol just as parathyroid hormone promotes the production of 1,25-dihydroxycholecalciferol.

The coincidence of hypoparathyroidism and medullary thyroid carcinoma may occur again; it will be interesting to discover whether further cases are resistant to vitamin $\mathrm{D}$ and whether they respond to small doses of 1,25-dihydroxycholecalciferol.

This patient was under the care of Professor J Crooks, Dr R N Johnston, Dr J L Lindsay, Mr A G D Maran, Mr R Pringle, and Dr R Semple; I am indebted to them for advice and permission to report the case. I thank Professor I MacIntyre for the calcitonin essay.

${ }^{1}$ Ireland, A W, et al, Annals of Internal Medicine, 1968, 69, 81.

2 Russell, R G G, et al, Lancet, 1974, 2, 14.

3 Rösler, A, and Rabinowitz, D, Lancet, 1973, 1, 803.

${ }^{4}$ Rasmussen, H, et al, fournal of Clinical Investigation, 1972, 51, 2502.

5 Avioli, L V, Kidney International, 1972, 2, 241.

(Accepted 18 fanuary 1977)

Ninewells Hospital, Dundee DD1 9SY

C R PATERSON, DM, MRCPATH, senior lecturer in biochemical medicine 